\title{
COMPREENSÃO DE LEITURA DE PROFESSORES: IMPLICAÇÕES PARA PRÁTICAS DOCENTES
}

\author{
Adriana Benevides Soares \\ Professora Titular da Universidade Salgado de Oliveira, Professora Adjunta da Universidade do \\ Estado do Rio de Janeiro, Doutora em Psicologia Cognitiva pela Universidade de Paris XI. \\ Tereza Cristina Coutinho Corrêa Teixeira \\ Professora do Instituto Geremário Dantas, Mestre em Psicologia pela Universidade Gama Filho. \\ Márcia Maria Peruzzi Elia da Mota \\ Professora Titular da Universidade Salgado de Oliveira, Professora Adjunta da Universidade do \\ Estado do Rio de Janeiro, Doutora em Psicologia pela Oxford University.
}

\begin{abstract}
Resumo
Uma questão de interesse aos educadores diz respeito ao processo de compreensão de texto, habilidade fundamental para o progresso nos anos mais avançados de escolarização, e seu efeito nas práticas docentes. Esse é um estudo descritivo que explora essa questão. Utilizou-se um instrumento de compreensão de texto composto de perguntas sobre quatro níveis estruturais do texto e as práticas docentes foram descritas com base numa escala composta de quatro subescalas envolvendo: práticas cognitivas com enfoque lingüístico, aspectos cognitivos, afetivos e motores, formação continuada. Os resultados de 53 docentes mostraram uma leve tendência dos docentes a priorizar práticas cognitivas independente do seu nível de compreensão do texto.
\end{abstract}

Palavras-chave: compreensão de textos, práticas docentes, leitura.

\section{TEACHER'S READING COMPREHENSION: IMPLICATION FOR TEACHING PRACTICES}

\begin{abstract}
A question of interest for educational workers is the reading comprehension process, a fundamental ability for progress in more advanced years of schooling, and its effect on pedagogical practices. This is a study that explores this question. A reading comprehension instrument composed by four structural levels of text and a scale of pedagogical practice composed by four sub-scales involving: cognitive practices with linguistic focus, cognitive practices, affective and motor practices, continuous education, was used. The results of 53 children suggest a slight tendency of teacher to prioritize cognitive practices independently of their reading comprehension level.

Key-words: reading comprehension, docent practices, reading.
\end{abstract}

\section{COMPRENSIÓN LECTORA DE MAESTROS: IMPLICACIONES PARA LA PRÁCTICA DOCENTE}

\section{Resumen}

Una cuestión de interés para los educadores es el proceso de comprensión de textos, capacidad fundamental para el progreso en los últimos años de escolaridad, y su efecto en prácticas de enseñanza. Este es un estudio descriptivo que analiza este. Se utilizó una herramienta para la comprensión de texto compuesto por preguntas en 
cuatro niveles estructurales del texto y prácticas de enseñanza se describen sobre la base de una escala compuesta que afecta a cuatro subescalas: las prácticas cognitivas centrándose la formación lingüística, cognitiva, afectiva y motora, continuó. Los resultados de 53 profesores mostraron un ligero tendencia de los profesores para dar prioridad a las prácticas cognitivas independientemente de su nivel de comprensión del texto.

Palabras clave: comprensión de lectura, prácticas de enseñanza, la lectura.

\section{INTRODUÇÃO}

É quase um senso comum afirmarmos que a leitura é um aspecto fundamental para o desempenho escolar. Sem ela não compreendemos problemas matemáticos, teremos dificuldades nas mais diversas matérias: Português, História, Geografia entre outras. Assim, um grande número de pesquisas e subseqüentes debates têm sido travados no âmbito do ensino da língua escrita. Porém, esse debate tem se concentrado nas questões básicas da alfabetização (Ferreiro \& Teberosky, 1979; Capovilla \& Capovilla, 2001; Mota, 2007). Menos é discutido sobre o que acontece nos anos posteriores, após o início do ensino formal da língua escrita (Oliveira \& Santos, 2005).

Uma questão de interesse nesse debate diz respeito ao processo de compreensão de texto, habilidade fundamental para o progresso nos anos mais avançados de escolarização. A compreensão de um texto envolve a construção de representações mentais que por sua vez envolve um emparelhamento entre $o$ estímulo textual e o conhecimento de mundo que é realizado através de processos mnemônicos e inferenciais.

Segundo Rossi e Bert-Erboul (1990) a compreensão de um texto supõe que o leitor identifique as informações importantes para construir uma representação de base do texto, associando às argumentações do autor. A identificação das informações importantes não pode ser vista de forma unívoca. De fato, há duas grandes categorias: a importância estrutural e a importância atribuída pelo leitor ou importância subjetiva. A importância subjetiva está ligada ao fato do leitor apreciar as informações contidas no texto. Porém, a importância estrutural não se define em relação ao leitor, mas sim em relação ao autor. Os textos apresentam objetivo principal, intermediários ou secundários e uma boa compreensão da base do texto necessita da integração de uma estrutura hierarquizada de diferentes objetivos.

O texto pode ser analisado quanto a sua superestrutura que se refere a aspectos globais do texto que possuem uma forma de organização definida e 
coerente. A macroestrutura de um texto, por sua vez, são as idéias ou proposições em torno das quais cada um dos significados particulares encontra um sentido, portanto, elas servem para dar um sentido, uma unidade e uma coerência global ao texto. A argumentação de um texto diz respeito às justificativas que levam a afirmar a macroestrutura, ou seja, defender a idéia central. Os detalhes consistem nos pormenores, nas particularidades e minúcias da macroestrutura. As inferências são informações que não estão explícitas no texto, mas que poderão influenciar no processo de compreensão do mesmo.

Segundo alguns autores (Rossi, 1990; Miguel, 2002; Bottino, 2004) bons compreendedores de texto apresentam poucas dificuldades em relação ao significado das palavras; trabalham bem a microestrutura textual; demonstram capacidade de definir a macroestrutura; determinam com facilidade a organização textual (superestrutura); apresentam compreensão profunda que permite resolver problemas novos; utilizam estratégias metacognitivas adequadas; utilizam-se muito de estratégias retóricas; constroem representação estruturada das informações importantes a partir da estrutura geral do texto; apresentam esquemas mais bem desenvolvidos, facilitando a memória; demonstram maior facilidade na determinação da macroestrutura e argumentação; utilizam-se da estratégia de, a partir da estrutura geral, tratarem a argumentação desenvolvida no texto, indo além da macroestrutura geral. Precisam de pouca ou nenhuma ajuda externa para a compreensão.

Os compreendedores menos proficientes de texto por sua vez apresentam dificuldades quando não reconhecem o significado das palavras; demonstram dificuldades em correlacionar as proposições presentes no texto (microestrutura); apresentam dificuldades em determinar uma ou mais proposições globais (macroestrutura); influenciam-se mais facilmente pela "forma" de apresentação textual (superestrutura); apresentam compreensão superficial; demonstram maior dificuldade na auto-regulação e utilização de estratégias metacognitivas adequadas; utilizam-se bastante do "frame" (estrutura de integração de conhecimentos coerentes armazenados na memória e acessados para facilitar a compreensão) na compreensão de textos científicos; selecionam as informações importantes a partir de indicações lexicais constituintes numa lista de informações incompletas e não estruturadas; apresentam esquemas não tão bem desenvolvidos, dificultando, assim a 
recuperação de informações na memória; apresentam dificuldades na capacidade de argumentação.

Em relação à determinação de detalhes e inferências a serem observadas a partir do texto lido, os estudos não apontam para a existência de diferenças entre bons e maus compreendedores de texto. Concluímos que o processo de compreensão textual é bastante complexo, na medida que envolve aspectos cognitivos. A compreensão de um discurso se apresenta ao leitor como um problema a ser resolvido, alguns realizam esta tarefa com bastante sucesso, outros necessitam despender de um número maior de recursos. Porém, não podemos desconsiderar que fatores externos poderão facilitar ou dificultar esta tarefa, como por exemplo, um texto mal elaborado, ou seja, sem clareza e coesão, bem como, a utilização de um texto, por parte do docente, inadequado à faixa etária de uma criança.

Dentre os fatores apontados como causa das dificuldades de leitura apontase o professor como leitor. Há muito se discute o papel do professor no desenvolvimento do gosto pela leitura de seus estudantes (Kato, 1999; Sandroni e Machado, 1998; Zorzi, 2003), e o papel da escola nesse processo (Bamberger, 2002; Jolibert, 1994; Rangel, 2002; Villardi, 1999), porém poucas evidências empíricas foram levantadas a respeito de como o "professor como leitor" afeta sua prática pedagógica. Esse artigo tentar cobrir essa lacuna na literatura. A presente pesquisa pretende analisar o seguinte:

A questão levantada é se o fato do docente ser um bom compreendedor ou um compreendedor pouco proficiente de textos pode influenciar sua prática docente. Para responder a essa pergunta o desempenho dos participantes desse estudo foi avaliado através da aplicação de um instrumento de compreensão de leitura. O instrumento constava de vinte e uma questões abertas de compreensão textual, que deveriam ser respondidas a partir da leitura de um texto, com 5 perguntas envolvendo a Macroestrutura, 6 perguntas envolvendo Argumentação, 5 perguntas envolvendo Detalhes, e mais 5 perguntas destinadas às Inferências. Os professores foram classificados de acordo com seu desempenho nessa tarefa. Se professores que são bons compreendedores apresentam uma prática docente diferenciada, encontraremos mudanças qualitativas na forma que professores que são bons e maus compreendedores trabalham em sala de aula. 
A variável "prática docente" foi observada por instrumento construído, visando identificar as práticas pedagógicas freqüentemente utilizadas pelos docentes, subdividido em quatro subescalas: $1^{\text {a }}$ subescala são práticas que tendem a influenciar no desenvolvimento dos aspectos cognitivos do discente com enfoque à compreensão lingüística; $2^{a}$ subescala são práticas que tendem a influenciar no desenvolvimento dos aspectos cognitivos do discente com enfoque ao desenvolvimento global; $3^{a}$ subescala são práticas que tendem a influenciar no desenvolvimento dos aspectos afetivo/motor do discente; $4^{a}$ subescala são práticas que tendem a influenciar na formação continuada do docente.

\section{MÉTODO}

\section{Participantes}

A amostra total estudada contemplou 53 docentes participantes, sendo 30 profissionais de Língua Portuguesa, 15 de História, 2 de Filosofia, 2 de Religião e 4 de Geografia, sendo que 26 destes docentes só são graduados, 24 possuem alguma especialização em nível de pós-graduação lato-sensu e 3 possuem o título de mestre. Em relação ao tempo de magistério há uma variação entre 1 a 30 anos de experiência, com maior concentração de profissionais com 1 a 5 anos de magistério $(N=21)$, seguido de 6 a 15 anos $(N=10)$ e 11 a 15 anos $(N=30)$ de profissão.

\section{Instrumentos}

\section{Questionário de compreensão}

Foi utilizado um texto expositivo adaptado pela pesquisadora: "Depressão em Crianças e Jovens", extraído da Revista SINPRO, autoria de Barbirato (2004), constituído de 656 palavras e 11 parágrafos. Para esta pesquisa foram utilizadas 16 questões abertas onde os sujeitos leram e responderam a 3 perguntas envolvendo a Macroestrutura, 4 perguntas envolvendo Argumentação, 5 perguntas envolvendo Detalhes, mais 4 perguntas destinadas às Inferências. 0 coeficiente de fidedignidade desse questionário foi de $0,7 .{ }^{1}$

A macroestrutura de um texto é composta por idéias ou proposições em torno das quais cada um dos significados particulares encontra um sentido, portanto, elas servem para dar um sentido, uma unidade e uma coerência global ao texto. A argumentação de um texto é a prova que serve para afirmar a

\footnotetext{
${ }^{1}$ Os procedimentos de construção dessa escala são descritos em outro artigo em preparação.
}

176 Estudos Interdisciplinares em Psicologia, Londrina, v. 1, n. 2, p. 172-183, dez. 2010 
macroestrutura, ou seja, defender a idéia central. Os detalhes consistem nos pormenores, nas particularidades e minúcias da macroestrutura. As inferências são informações que não estão explícitas no texto, mas que poderão influenciar no processo de compreensão do mesmo. As perguntas foram apresentadas da seguinte forma: da questão 1 à 3 os itens referem-se à macroestrutura; da questão, 4 à 7 os itens referem-se à argumentação, da questão 8 à 12 os itens referem-se à detalhes e da questão 13 à 16 os itens referem-se à inferências. Os participantes tiveram tempo livre para a execução da atividade. A correção foi feita a partir de um gabarito e as respostas foram consideradas certas ou erradas. As respostas foram avaliadas por 2 juízes.

\section{Questionário de Práticas Docentes}

Consiste de um questionário composto de 4 subescalas constando de 70 itens avaliados por uma escala tipo Lickert vairando de 1 - realizo pouquíssimo a 5 - realizo muitíssimo. A primeira subescala tem 21 itens e contemplam as práticas que tendem a influenciar no desenvolvimento dos aspectos cognitivos do discente com enfoque à compreensão lingüística, a segunda de 28 itens se refere a práticas que tendem a influenciar no desenvolvimento dos aspectos cognitivos do discente com enfoque ao desenvolvimento global, a terceira de 11 envolve as práticas que tendem a influenciar no desenvolvimento dos aspectos afetivo/motor do discente e a quarta, de 10 itens se refere a práticas que tendem a influenciar na formação continuada do docente. O coeficiente de fidedignidade deste instrumento foi de 0, 9584.

$1^{\text {a }}$ subescala - Práticas que tendem a influenciar no desenvolvimento dos aspectos cognitivos do discente com enfoque à compreensão lingüística.

$2^{a}$ subescala - Práticas que tendem a influenciar no desenvolvimento dos aspectos cognitivos do discente com enfoque ao desenvolvimento global.

$3^{a}$ subescala - Práticas que tendem a influenciar no desenvolvimento dos aspectos afetivo/motor do discente.

$4^{a}$ subescala - Práticas que tendem a influenciar na formação continuada do docente.

\section{Procedimentos}

Os sujeitos leram e assinaram o termo de consentimento livre, preencheram o questionário de dados demográficos e responderam aos dois 
instrumentos (Compreensão Textual e Práticas Docentes). No instrumento de compreensão de texto, as questões foram consideradas certas ou erradas, observando o número de acertos e erros, nas questões de macroestrutura, argumentação, detalhes e inferências, separadamente. A correção foi feita a partir do gabarito e as respostas foram consideradas certas ou erradas. Como são questões abertas, o gabarito serviu como orientação na correção, onde as questões foram dadas como corretas na medida em que apresentaram a idéia central da resposta observando o comando da questão.

Para a variável práticas docentes, a partir da escala Likert foi calculado um escore total para cada subescala. Para atender aos objetivos da investigação o segundo instrumento passou por validação. ${ }^{2}$

\section{RESULTADOS}

No instrumento de práticas docentes foi construído um indicador. Como há neste instrumento 4 subescalas, cada sujeito foi analisado a partir de seu desempenho em cada uma delas através de uma média. Existem vários tipos de médias, a utilizada foi a aritmética, definida pelo somatório dos resultados dividido por seu número. A partir destes dados estabeleceram-se análises qualitativas, considerando a classificação do sujeito como bom compreendedor ou compreendedor menos proficiente de texto e a utilização mais freqüente de práticas docentes.

Para responder essa primeira pergunta 53 docentes participantes foram classificados como bons ou compreendedores de texto menos proficientes a partir da aplicação do instrumento de compreensão textual, e, após o tratamento estatístico os resultados para esta classificação foram de 58,5\% (freqüência igual a 31) de bons compreendedores e 41,5\% (freqüência igual a 22) de compreendedores de texto menos proficientes.

A classificação de bons e compreendedores menos proficientes se estabeleceu a partir do cálculo da mediana, considerando-se o número de acertos e não a amostra, que possibilita a caracterização do grupo como um conjunto tendendo a se condensar no centro da série, ou seja, uma medida de tendência central. As três medidas de tendência central, coincidentemente apresentam mediana igual à moda, apesar disso ser incomum: média igual a

\footnotetext{
2 o procedimento de validação é discutido em outro artigo em preparação.
}

178 Estudos Interdisciplinares em Psicologia, Londrina, v. 1, n. 2, p. 172-183, dez. 2010 
12,49; mediana e moda igual a 13, sendo o mínimo de acertos igual a 7 e o máximo de acertos igual a 16.

Portanto, os sujeitos que acertaram de 13 a 16 questões foram classificados como bons compreendedores de texto, e os docentes com o número de acertos entre 7 a 12 questões foram classificados como compreendedores menos proficientes de texto. Os 53 docentes participantes foram classificados, após o tratamento estatístico foram classificados da seguinte forma: 58,5\% (freqüência igual a 31) de bons compreendedores e 41,5\% (freqüência igual a 22) de compreendedores de texto menos proficientes.

Após a análise classificatória de bons e compreendedores e compreendedores menos proficientes de texto, foi analisado o instrumento de práticas docentes, dividido em 4 subescalas. As subescalas foram analisadas separadamente da seguinte forma: considerando os resultados individuais dos sujeitos participantes, foram somados os itens da escala Lickert por subescalas e dividido pelo número de itens das mesmas, chegando individualmente à verificação de qual subescala é mais freqüentemente utilizada pelo docente. $A$ partir daí foi retirado uma média de freqüência de utilização de práticas docentes na amostra testada.

Tabela 1.

Preferência de utilização de práticas docentes.

\begin{tabular}{|c|c|c|c|}
\hline & \multicolumn{2}{|c|}{ Classificação } & \multirow[b]{2}{*}{ Total } \\
\hline & $\begin{array}{l}\text { Compreendedor } \\
\text { menos proficiente }\end{array}$ & $\begin{array}{c}\text { Bom } \\
\text { compreendedor }\end{array}$ & \\
\hline $1^{\text {a }}$ Subescala & 3.87 & 3.80 & 3.83 \\
\hline $2^{\text {a }}$ Subescala & 4.08 & 4.09 & 4.08 \\
\hline 3a Subescala & 3.74 & 3.71 & 3.72 \\
\hline $4^{a}$ Subescala & 4.00 & 3.95 & 3.97 \\
\hline
\end{tabular}

A Tabela 1 mostra a freqüência de utilização de práticas docentes em cada grupo. Considerou-se uma comparação de bons e compreendedores menos proficientes de texto e a freqüência da utilização de práticas docentes, que foram separadas em subescalas, porém, independente do docente ser bom ou menos proficiente, constatou-se que todos os participantes se utilizam mais freqüentemente das práticas, obedecendo a seguinte ordem: $2^{a}$ subescala, que refere-se a práticas que tendem a influenciar no desenvolvimento dos aspectos cognitivos do discente com enfoque ao desenvolvimento global; $4^{a}$ subescala, 
que refere-se a práticas que tendem a influenciar na formação continuada do docente; $1^{a}$ subescala, que refere-se a práticas que tendem a influenciar no desenvolvimento dos aspectos cognitivos do discente com enfoque à compreensão lingüística, e, por último a $3^{a}$ subescala, que refere-se a práticas que tendem a influenciar no desenvolvimento dos aspectos afetivo/motor do discente. Pode-se ver que o grupo de bons compreendedores e maus compreendedores utilizaram as quatro subescalas de forma equivalente, e que a média entre as diferentes escalas também foi equivalente nessa amostra.

\section{DISCUSSÃO E CONSIDERAÇÕES FINAIS}

Jolibert (1994) discute e analisa a teoria e ação pedagógica com o objetivo de formar crianças leitoras, sabemos que a leitura é uma construção singular, de cada sujeito, mas que ocorre com maior potencialidade em situações reais, vividas em grupo, com um objetivo claro e coordenado pela intervenção do docente. Portanto, sem uma proposta clara, estimuladora do processo de desenvolvimento da leitura por parte do profissional da educação, possivelmente - discente poderá apresentar maior dificuldade no desenvolvimento da capacidade de compreensão de um discurso, até mesmo arrastando esta situação após a conclusão do curso universitário, pois a leitura é uma atividade complexa que envolve a intervenção de diversos processos (Salles \& Parente, 2004). Nesse sentido, procurou-se observar nesse estudo um dos fatores apontados na literatura o professor como leitor.

Vale a pena ressaltar que Kintsch (1988) observa que os níveis de compreensão textual são categorias analíticas, mas que a cognição, utilizada neste processo, funciona como um todo. Delval (2001) quando faz um estudo em sua obra: "Aprender na vida e aprender na escola", relata que a atividade de ensino, ou seja, a prática pedagógica depende de uma série de requisitos, como por exemplo, para poder ensinar, o docente precisa fazer conjecturas sobre o estado mental do aprendiz. Deve colocar-se em sua perspectiva e tomar consciência do que não pode fazer ou não entende e de quais são os obstáculos que encontra, e, como intervir para ajudar o aprendiz. Diante de tantos aspectos a serem considerados no processo de aprendizagem, possivelmente, os docentes estão mais preocupados com o desenvolvimento da cognição como um todo, ou seja, da capacidade do educando em resolver um leque maior de problemas, demonstrando aprendizagem em diferentes áreas do conhecimento, do que com 
a especificidade do desenvolvimento da capacidade de compreensão de um discurso. Apesar das diferenças nos escores de uso das várias subescalas não serem acentuadas, a pesquisa demonstra uma preferência dos docentes, independente de serem bons ou compreendedores menos proficientes de texto, primeiramente, pela $2^{\mathrm{a}}$ subescala. Essa última, refere-se às práticas que tendem a influenciar no desenvolvimento dos aspectos cognitivos do discente, com enfoque ao desenvolvimento global, sendo práticas que, não necessariamente, irão agir na especificidade do desenvolvimento da compreensão textual.

Para todos os sujeitos participantes, a segunda subescala mais utilizada foi a quarta, que são práticas que tendem a influenciar na formação continuada do docente. Esta preocupação com a formação continuada pode ser em conseqüência de que, a prática pedagógica muda, lenta, mas profundamente. Administrar sua própria formação contínua é a décima competência profissional descrita por Perrenoud (2000). Esta prática evidencia algumas competências específicas, como por exemplo: saber explicitar as próprias práticas; estabelecer seu próprio balanço de competências e seu programa pessoal de formação contínua; negociar um projeto de formação comum com os colegas; envolver-se em tarefas de ensino ou do sistema educativo; acolher a formação dos colegas e participar dela. Todas estas competências parecem indispensáveis ao profissional da área de educação diante de um mundo em constante mutação.

A $3^{\text {a }}$ subescala mais utilizada foi a $1^{\text {a }}$ subescala que é a de práticas que tendem a influenciar no desenvolvimento dos aspectos cognitivos do discente com enfoque à compreensão lingüística. Estas se apresentam em $3^{\circ}$ lugar de preferência dos docentes. Este resultado pode ser explicado uma vez que a $2^{a}$ subescala suplanta a $1^{\text {a }}$ subescala em função da abrangência que a primeira tem sobre a segunda, pois a $2^{a}$ subescala envolve práticas de desenvolvimento mais global dos processos cognitivos, enquanto a $1^{\text {a }}$ subescala trabalha com a especificidade do desenvolvimento da compreensão e capacidade lingüística.

A última subescala mais utilizada foi a $3^{a}$ subescala, referente a aspectos afetivo/motor, que certamente possui sua importância no desenvolvimento global do discente, mas não abrange com veemência os processos cognitivos subjacentes ao processo de aprendizagem. Destacamos, no entanto, que a diferença na preferência entre essas escalas foi muito baixa entre os professores. Impossibilitando que esse estabeleça um padrão típico de prática docente. Os 
resultados sugerem que os professores apresentam diferentes padrões de prática docente.

Quanto às diferenças entre bons e maus leitores, não parecem influenciar as práticas docentes. O padrão de escolha das práticas foi semelhante entre os grupos foi semelhante. Uma ressalva precisa ser feita a esse respeito, a divisão entre bons e maus compreendedores nesse estudo foi arbitrária. É possível que nossa divisão não tenha adequadamente discriminado bons e maus leitores.

\section{REFERÊNCIAS}

Barbirato, F. (2004). Depressão em crianças e jovens. Revista Sinpro, 6, 48-54. Bottino, A. G. (2004). Compreensão da linguagem na educação de jovens e adultos. Dissertação de Mestrado. Rio de Janeiro: Universidade Gama Filho. Bamberger, R. (2002). Como incentivar o hábito de leitura. São Paulo: Ática.

Capovilla, A. \& Capovilla, F. (2001). Alfabetização e método fônico. São Paulo: Mnemom.

Delval, J. (2001). Aprender na vida e aprender na escola. Porto Alegre: Artmed. Ferreiro, E. \& Teberosky, A. (1979). Psicogênese da língua escrita. Porto Alegre:

Editora Artes Médicas.

Jolibert, J. (Orgs.) (1994). Formando crianças leitoras: vol I. Porto Alegre: Artmed.

Kato, M. (1999). O aprendizado da leitura. São Paulo: Martins Fontes.

Kintsch, W. (1988). The role knowledge in discourse comprehension: a construction model. Psychological Review, 95(2), 163-182.

Miguel, E. (2002) Compreensão e redação de textos: dificuldades e ajudas. Porto Alegre: Artmed.

Mota, M. M. P. E. (2007) Algumas considerações sobre o letramento e o desenvolvimento metalingüístico e suas implicações educacionais. Estudos e Pesquisas em Psicologia (UERJ), 7(3), 118-130.

Oliveira, K. L. de, \& Santos, A. A. A. (2005). Compreensão em leitura e avaliação da aprendizagem em universitários. Psicologia Reflexão e Crítica, 18(1), 118-124.

Perrenoud, P. (2000). Dez novas competências para ensinar. Porto Alegre : Artmed Editora.

Rangel, M. (2002). Dinâmicas de leitura para sala de aula. Rio de Janeiro: Editora Vozes. 
Rossi, J. P. (1990). The function of frame in the comprehension of scientific text. Journal of Education Psychology, 82, 727-732.

Rossi, J. P. \& Bert-Erboul, A. (1990). Comprehension de textes et fonctions informatives des phases. Centre d'Etudes de Psychologie Cognitive, document n० 86.

Salles, J. F., \& Parente, M. A. P. P. (2004). Compreensão textual em alunos de segunda e terceira séries: uma abordagem cognitiva. Estudos de Psicologia, $9(1), 71-80$.

Sandroni, L. \& Machado, L. R. (1998) A criança e o livro: Guia prático de estímulo à leitura. São Paulo: Ática.

Villardi, R. (1999). Ensinando a gostar de ler e formando leitores para a vida inteira. Rio de Janeiro: Qualitymark/Dunya.

Zorzi, J. L. (2003). Análise de atitudes e hábitos de leitura em escolares de $1^{0}$ grau. Temas em Educação II - Livro das Jornadas, 107-122.

Contato: adribenevides@gmail.com

Recebido em: 13/10/2010

Revisado em: 03/11/2010

Aceito em: 07/12/2010 